\title{
Distribution and Current State Cenopopulations of Helichrysum maracandicum Popov ex Kirp. in Uzbekistan
}

\author{
Alisher N. Khujanov \\ Institute of Botany Academy Science Republic of Uzbekistan, Tashkent, Uzbekistan \\ Email: ozodbek88@bk.ru
}

How to cite this paper: Khujanov, A.N. (2019) Distribution and Current State Cenopopulations of Helichrysum maracandicum Popov ex Kirp. in Uzbekistan. American Journal of Plant Sciences, 10, 1280-1286. https://doi.org/10.4236/ajps.2019.108092

Received: July 3, 2019

Accepted: August 9, 2019

Published: August 12, 2019

Copyright $\odot 2019$ by author(s) and Scientific Research Publishing Inc. This work is licensed under the Creative Commons Attribution International License (CC BY 4.0).

http://creativecommons.org/licenses/by/4.0/

\section{cc (i) Open Access}

\begin{abstract}
The current state of coenotic populations of rare and endangered species of Uzbekistan Helichrysum maracandicum is given. The range of species distribution is broad. The article contains 12 cenopopulations of Helichrysum maracandicum in Uzbekistan, which have considerable healing properties. During the researches, no censorship marks were recorded in any cenopopulation. Approximately, 1, 5, 11 censorpopulations were found to be close to optimal conditions. This indicates that adequate amounts of precipitation in these areas throughout the year have a positive impact on the growth and development of the plant. Most of the cenopopulations were transmitted to younger and transient states.
\end{abstract}

\section{Keywords}

Helichrysum maracandicum, Current State, Cenopopulations, Plant Community, Uzbekistan

\section{Introduction}

The development of industry and agriculture and the extensive use of natural areas lead to the breakdown of the ecological balance. As a result, there is a risk of diminishing the number of plant species. Despite the relatively good overall state of the species preserved in the national reserves, natural resources of many wild species are sharply declining.

Especially demand for medicinal plants is rising day by day. This affects the status of species in natural populations. Among these species are H. maracandicum, which plays an important role in terms of medicinal activity.

However, there have been no studies on cenopopulations and natural re- 
sources of the Helichrysum range, which has been spread to our country so far. Research on the current state of cenopopulation allows the study of ecological optimum species at the level of population and organism level. Scientists have noted that in assessing the state of cenopopulation, individual and population optimally are differentiated. Because the maximum value of organisms and population marks is not always the same, and in some cases, they have absolutely the opposite value. Today, scientists have developed a number of methodological manuals that can help identify the optimal, critical and pessimistic cenopopulations.

\section{Research Objects and Methods}

The object of our research is the type of $H$. maracandicum spread throughout Uzbekistan (Figure 1).

$H$. maracandicum's cenopopulations were evaluated on the basis of a number of organisms and population signs [1].

During the study, 12 cenopopulations (CP) of $H$. maracandicum were evaluated a number of organisms and populations have been studied to assess the state of cenopopulation. The reliability of differences between the mean values of the marks studied was evaluated according to the criteria of Student. The reliability of markers in screeners is less than 2.0, and the relative censorship values are close to each other. Characters with a score of 2.0 or higher mean the difference between the average values. For all organism marks, the mean value of the 10 rats of the generative age was derived from all cenopopulation.

Transects were laid a length of $10 \mathrm{~m}$, they were divided in area for $1 \mathrm{~m}^{2}$. Each coenopopulations laid from 10 to 30 sites over $1 \mathrm{~m}^{2}$. Ontogenetic structure cenopopulation was defined as the ratio in populations of individuals of different

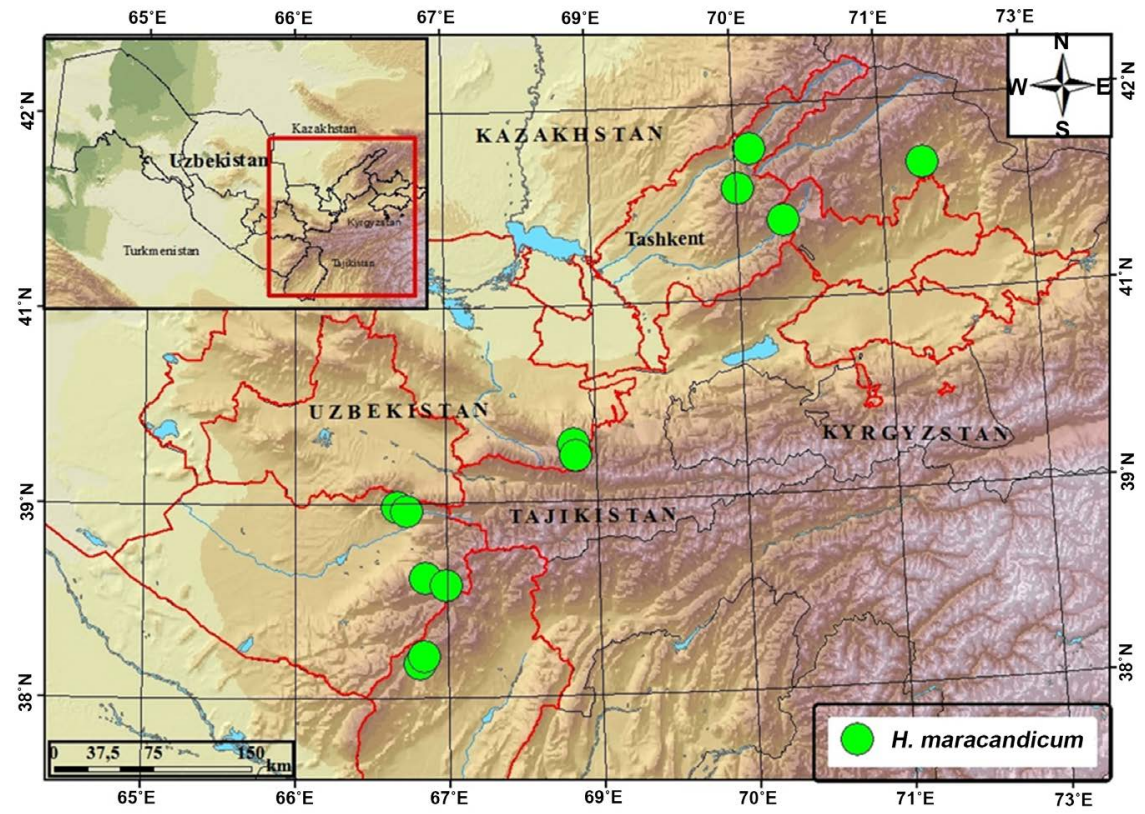

Figure 1. Schematic map of the study area. 
developmental states. An individual was taken for the unit of account. At characterization of the population structure based on the idea of the typical ontogenetic spectrum [1], 4 types of spectrum are emphasized by the nature of the ontogenetic groups distribution: left-sided, centered, right-sided and bimodal. The typical range is dependent on the biological characteristics of the species. Cenopopulations described according to the classification of A.A. Uranov and O.V. Smirnova [2] and classification "delta-omega" of L.A. Jivotovsky [3]. Delta $(\Delta)$-An index of population age [4], which assesses the age level of coenopopulations at any moment of time, and omega $(\omega)$-The effectiveness of the plant i-ontogenetic state (the value of "load" on the energetic resources of environment, expressed as a fraction load produced by middle-aged generative condition plants of this population. According to this classification, the CP can be young, ripening, transition, aging and old. The population density was determined by the number of individuals or biomass on per unit area. Particular attention was paid to the average density, i.e. the number of per unit whole space or ecological density-the number of per unit habitable space that can actually be occupied by population [5]. Geobotanical descriptions were made by standard methods at the sites of $100 \mathrm{~m}^{2}$ [6]. Plant name was given by Cherepanov [7].

\section{Results and Discussion}

To estimate of the coenopopulation state as organismic traits we selected: Plant height, cm; Leaf length, cm; Leaf weight, cm; Number of saucers, pcs; Individual's biomass, g; Density of individuals per $1 \mathrm{~m}^{2}$; ecological density of individuals per $1 \mathrm{~m}^{2}$; the proportion of young individuals fraction $(j-v)$; the proportion of individuals of generative fraction $(\mathrm{g})$; the proportion of individuals of old fraction (s) were taken as the population signs. To assess of the coenopopulation state a range of selected features are divided into five classes with the same amount on an equable scale; then each class was assigned a score; lowest score corresponded to the lowest indicators (Table 1). The evaluation results are presented in the form of a multi-axis chart.

In order to assess the state of the cenopopulation, each of the characters has been divided into five groups of the same size. Then each group is given a score, which is the lowest point. The results of the assessment of the state of cenopopulation are reflected in the multi-diagram (Table 1 ).

The low value of marks is due to the increase of cenopopulation on small-sand, crushed and crushed soils and low annual precipitation. Along with the above factors, the regular increase in fattening levels over livestock leads to the deficit of organic matter in the soil. This, in turn, leads to lower levels of organism symptoms. An analysis of the organism and population's symptoms in the tour indicates that none of the censorpopulations found in the tour found the maximum value of the mark. However, according to the value of all selected organisms and population signs, weeds are represented by various herbivorous (CP-1) surrounding village Machay, a variety of herbs in the Kizil-Korium 
Table 1. Schematic map of the study area.

\begin{tabular}{|c|c|c|c|c|c|c|}
\hline \multirow{2}{*}{ № } & \multirow{2}{*}{ Signs } & \multicolumn{5}{|c|}{ Points } \\
\hline & & I & II & III & IV & $\mathrm{V}$ \\
\hline 2 & Leaf length, $\mathrm{cm}$ & $5.3-5.93$ & $5.94-6.57$ & $6.58-7.21$ & $7.22-7.85$ & $7.86-8.5$ \\
\hline 3 & Leaf weight, $\mathrm{cm}$ & $0.30-0.38$ & $0.39-0.47$ & $0.48-0.56$ & $0.57-0.65$ & $0.66-0.72$ \\
\hline 4 & Number of saucers, pcs & $43-52.1$ & $52.2-61.3$ & $61.4-70.5$ & $70.6-79.7$ & $79.8-89$ \\
\hline 5 & Individual biomass, $\mathrm{g}$ & $28-35.3$ & $35.4-42.7$ & $42.8-50.1$ & $50.2-57.5$ & $57.5-65$ \\
\hline 6 & $\begin{array}{l}\text { The individuals density of species } \\
\text { per } 1 \mathrm{~m}^{2} \text {, pieces. }\end{array}$ & $3.4-5.1$ & $5.11-6.81$ & $6.82-8.52$ & $8.53-10.23$ & $10.24-12$ \\
\hline 7 & Ecological density of $1 \mathrm{~m}^{2}$, pieces. & $4.25-6.05$ & $6.06-7.86$ & $7.87-9.67$ & $9.68-11.48$ & $11.49-13.3$ \\
\hline 9 & Proportion g2 - g3 (\%) & $15.37-20.79$ & $20.80-26.22$ & $26.23-31.65$ & $31.66-37.09$ & $37.1-42.49$ \\
\hline 10 & Proportion j - g1 (\%) & $35.7-44.24$ & $44.25-52.80$ & $52.81-61.36$ & $61.37-69.92$ & $69.93-78.45$ \\
\hline
\end{tabular}

surrounding Amankotan village (CP-5) and the plant communities separated by the Nanay village of Bostanlik region (CP-11) high levels of organisms and population signs. These cenopopulations, the height of the plant tailings was around $54.6-72 \mathrm{~cm}$. This, in turn, has a positive impact on biophysics. The biomass of tubers was 50.2 - 65 gramm in these cenopopulations. The number of baskets per plant is 70.6 - 89. High screening symptoms are due to the high levels of precipitation throughout the year, as well as relatively abiotic and biotic effects. This condition has allowed the organism to be high (Figure 2).

The censorships mentioned above were the highest indicator of the population. At the area of 1 sq. M., the appearance of the bark is $6.92-12$ and the ecological density of the bush is 9.68 - 13.3.

The mean value of organism and population counts was recorded in cenopopulations of 2, 8, and 9. Cenopopulation 2 was isolated from Kentala village, Boysun region, and recorded an adequate amount of precipitation throughout the year. 8 and $9 \mathrm{CP}$ were recorded in the mountainous area. This can be explained by the fact that in the zone of cenopopulation the moisture content is sufficient throughout the season. In these cenopopulations the average value of marks was 3 - 4 points. Specifically, in the mentioned cenopopulations, the height of the plant was $45.7-54.6 \mathrm{~cm}$. Accordingly, it was noted that the biomass of the bubbles is $42.8-50.2$ grams. The number of flakes in the plant is around $61.4-70.5$ gramm.

In these cenopopulations, the density of the densities and their ecological density were fairly reasonable. The density of the densities was $6.82-10.23$ in the recorded cenopopulation and 7.87 - 11.48 for ecological density.

The lower value of organism markers was recorded in 3, 4, 6, and 7 cases of cenopopulation. The lower value of the symptoms is associated with the area where the censorship is spread. These areas are closer to population dwellings 

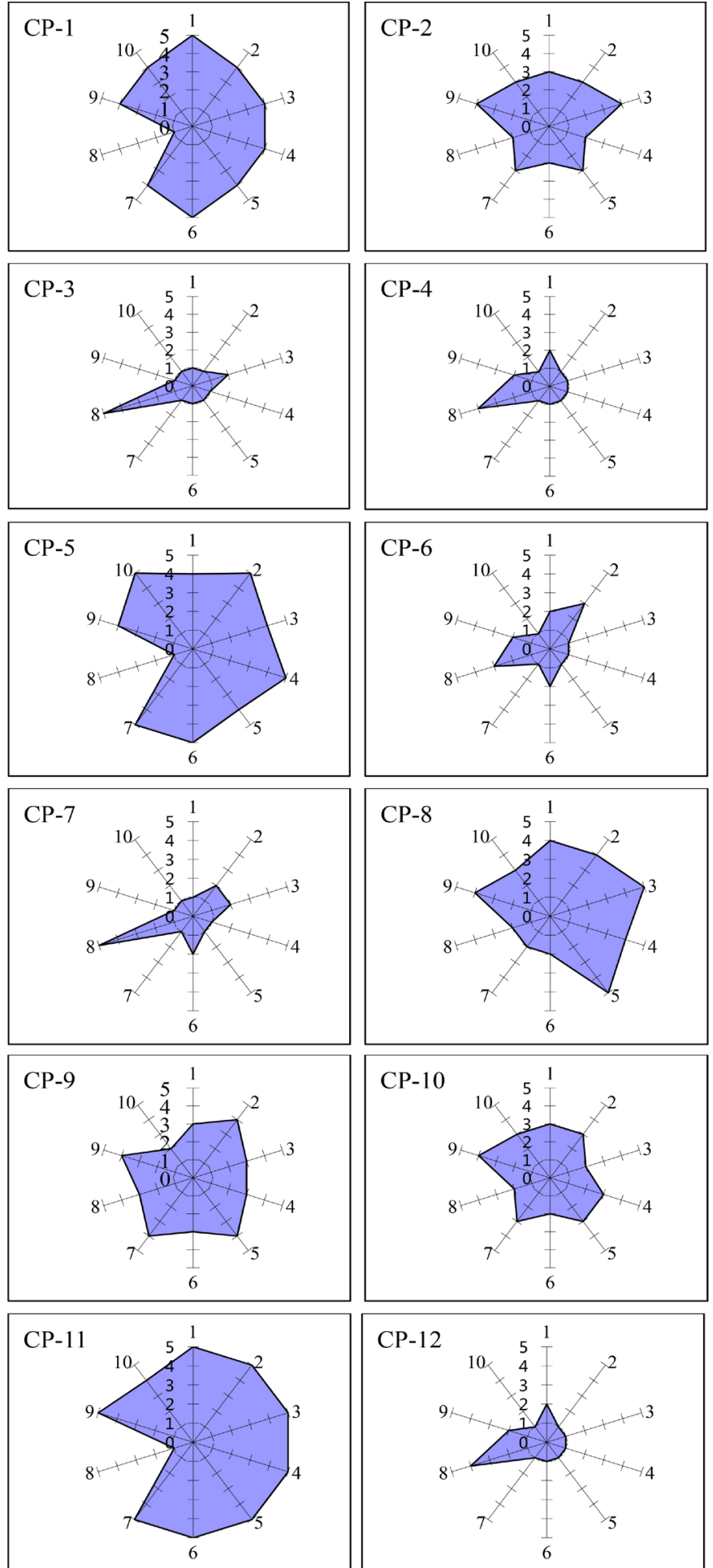

Figure 2. Assessment of $H$. maracandicum cenopupulation (in points). Organismic signs: 1 -Plant height, $\mathrm{cm}$; 2-Leaf length, $\mathrm{cm}$; 3-Leaf weight, $\mathrm{cm}$; 4-Number of saucers, pcs; 5-Individual biomass, g; Population signs: $6-H$. maracandicum individuals density on $1 \mathrm{~m}^{2}$; 7-ecological density of individuals $/ \mathrm{m}^{2}$ (pcs); 8 -share of old fraction (s); 9-generative fraction share (g1 - g2); 10-share of young fraction $(\mathrm{j}-\mathrm{g} 1)$. 


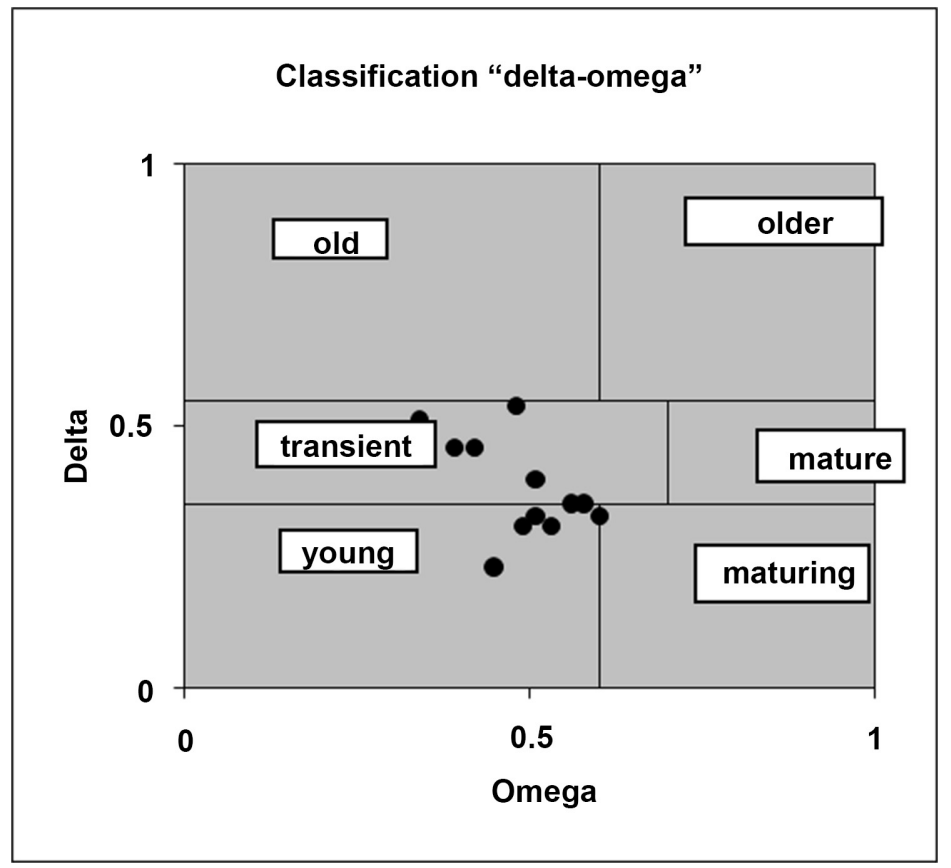

Figure 3. Types of cenopopulations (classification of delta-omega).

and regular feeding of livestock has led to lower values. The lowest number of symptoms was observed in 3 and 4 cenopopulations. Specifically, in these cenopopulations, the height of the plant was $28.37-36.7 \mathrm{~cm}$. The biomass of the tubes was recorded at $28-35.3$ gramm. In these cenopopulations with lower values, the number of boxes is $43-52.1$.

The lowest indexes of population density (ecological density and ecology) were recorded in these cenopopulations. In these cenopopgrats, the density of dyes does not exceed 5.1, the ecological density of the trees is about 4.25-6.05.

It was noted that the proportion of young players in the censorship does not differ from each other. This is due to the fact that the plant has a high potential for potential productivity and vegetative growth of the herbaceous. Particularly in one plant bush, there are between 35 and 80 baskets. The shaped baskets contain between 50 and 80 potent seeds. This is one of the most important factors in the recovery of cenopoplastic seeds. Given the fact that the plant is harvested locally, it is important that cerebral palsy be found in general. Decrease of generative buds in cenopopulation will naturally lead to a decrease in the number of seedlings in the next year.

During the study, the types of cenopopulation were analyzed. According to him, most cenopopulations were age-specific and transient (Figure 3).

\section{Conclusion}

In recent years, due to the rapid development of agriculture, anthropogenic pressing has been observed in wildlife. This situation is also reflected in the transformation of many natural areas into cultivated areas by the local population, and the rarely growing species of rice cultivation for commercial purposes. 
Thus, the diagnosis of $H$. maracandicum's cenopopulations states that none of the surveyed populations showed a maximum coincidence of the sum of characteristic values. This approach to the environment has resulted in a reduction in H. maracandicum's natural habitat and a sharp decline in some cenopopulations. The accurate geographical coordinates of these cenopopulations will then be used to conduct monitoring activities in those areas.

\section{Acknowledgements}

The current research is done under the project PZ-20170920219 "Establishment of interactive herbs in promising medicinal herbs in Uzbekistan (mainly monitoring and protection of the species in need of protection)".

\section{Conflicts of Interest}

The author declares no conflicts of interest regarding the publication of this paper.

\section{References}

[1] Zaugolnova, L.B. (1994) The Structure of the Populations of Seed Plants and Monitoring. Resume of Dissertation of Doctor of Biological Sciences, Sankt Petersburg, $70 \mathrm{p}$.

[2] Uranov, A.A. and Smirnova, O.V. (1969) Classification and Main Features of Development of Populations of Perennial Plants. Bulletin of Moscow Society of Naturalists (Department of Biology), 2, 119-134.

[3] Jivotovsky, L.A. (2001) Ontogenetic States, Effective, Density and Classification of Plant Populations. Russian Journal of Ecology, 32, 3-7.

[4] Uranov, A.A. (1975) Age Spectrum of Phytocoeno-Population as a Function of Time and Energy Wave Processes. Scientific Lectures of Higher Schools, Biological Sciences, 7-34.

[5] Odum, U. (1986) Ecological Density of Individuals. Ecology, 2, 209.

[6] Lavrenko, E.M., Korchagina, A.A. (1972) Field Geobotany. Academy Sciences SSSR, Leningrad, Vol. 4, 336.

[7] Czerepanov, S.K. (1995) Vascular Plants of Russia and Adjacent States (The Former USSR). Cambridge University Press, New York, 995 p. 